\title{
Anomalias hidroquímicas nos aquíferos de Icapuí/CE: riscos à saúde da população
}

Problemas de saúde coletiva e ambientais coexistem de forma integrada. Nesta sociedade, cada dia mais ansiosa, necessita-se de múltiplos meios e usos de novas tecnologias para analisar com olhar interdisciplinar, doenças emergentes e silenciosas e, outras, de diagnóstico difícil e origem não detectável. Este estudo visa avaliar os parâmetros bacteriológicos (coliformes totais e E. Coli), e de espécies químicas inorgânicas nitrogenados (amônia, nitrito e nitrato), de águas subterrâneas dos poços analisados na costa do município de Icapuí/CE, e, a existência ou não, de correlação com casos de doenças, por via hídrica, dos munícipes. A metodologia, referenciada na literatura, utilizada no laboratório, teve seus resultados correlacionados a dados secundários, quantitativos, de órgãos estatais. A presença de bactérias, E. Coli e coliformes totais, e de compostos nitrogenados, nas análises de águas coletadas em alguns poços da rede justifica o aumento dos casos, em Icapuí, de doenças diarreicas, no período da pesquisa, além do reaparecimento de casos de hepatite viral. Outros microorganismos podem estar associados, ficando como sugestão futura, pesquisas com médicos sanitaristas, para um diagnóstico preciso sobre outras possíveis enfermidades. Espera-se contribuir, por meio da divulgação do trabalho, com a gestão de saúde do município em melhorar a qualidade de vida dos nativos. Além de provocar, os formadores de profissionais da área, em buscar ultrapassar a limitação disciplinar, e diagnosticar, de forma mais rápida e correta, os mais diversos tipos de doenças.

\section{Hydrochemical abnormalaties in aquifers of the Icapui/CE: risk to health of the population}

\begin{abstract}
Public health problems and of the environmental coexist in an integrated way. In this society, very much more anxious, where if it needs multiple means and uses of new technologies to analysis, with an interdisciplinary view, about emerging and silent diseases, and others, with diagnosis, not clear and origin,undetectable. This study aims to evaluate the bacteriologica parameters and nitrogenous inorganic chemical species of groundwater from the wells analyzed in the coast side of Icapui City, State of Ceará, Brazilian Northeast. And, so too, the existence of correlation, or not, with cases of diseases, by water, in the local population. The methodology, referenced in the literature, and yet to used in the laboratory, it had its results correlated to secondary quantitative data of state organs. The presence of bacteria, E. Coli and total coliforms, and nitrogen compounds, in the samples of water collected in some wells in the network, justifies the increase in Icapuí cases of diarrheal diseases in the period of the research, in addition to the reappearance of cases of viral hepatitis. Other microorganisms may be associated, thus, as a future suggestion to new investigation, to inclued of the sanitary medical doctors researchers, for an accurate diagnosis of other possible diseases. Thus, It is hoped to contribute, thus, as a future suggestion to new investigation, to inclued of the sanitary medical doctors researchers, for an accurate diagnosis of other possible diseases. Thus, It is hoped to contribute, provoking, the professors of this professionals of the health, always to seeking the overcome the disciplinary limitation, in the formation of the graduate course, and to diagnose it, more quickly and correctly, the most diverse types of diseases.
\end{abstract}

Keywords: Health and Environmental; Hydrochemical; Medical Geology; Groundwater; Icapui.

Topic: Uso Sustentável da Biodiversidade

Reviewed anonymously in the process of blind peer
Received: 14/12/2017

Approved: 24/01/2018
Saulo Roberio Rodrigues Maia (iD

Universidade Federal do Ceará, Brasil

http://lattes.cnpq.br/2357110960992983

http://orcid.org/0000-0002-2523-3906

saulo.maia@uece.br

George Satander Sá Freire (D)

Universidade Federal do Ceará, Brasil

http://lattes.cnpq.br/6803944360256138

http://orcid.org/0000-0001-8850-7225

freire@ufc.br

Diolande Ferreira Gomes (iD

Universidade Federal do Ceará, Brasil

http://lattes.cnpq.br/0048357648552119

http://orcid.org/0000-0002-6296-0977

dfreire68@gmail.com
Karen Vendramini de Araújo (iD

Universidade Federal do Ceará, Brasil

http://lattes.cnpq.br/6253265513683634

http://orcid.org/0000-0001-5522-5299

karenvendramini@yahoo.com.br
Referencing this:

MAIA, S. R. R.; FREIRE, G. S. S.; GOMES, D. F.; ARAÚJO, K. V.. Anomalias hidroquímicas nos aquíferos de Icapuí/CE: riscos à saúde da população. Revista Ibero Americana de Ciências Ambientais, v.9, n.2, p.94-107, 2018. DOI: http://doi.org/10.6008/CBPC21796858.2018.002.0009

DOI: 10.6008/CBPC2179-6858.2018.002.0009 


\section{INTRODUÇÃO}

Doenças por veiculação hídrica, seja por contato direto, ingestão da água, por exemplo ou contato indireto, consumo de vegetais e animais presentes no mesmo ambiente; nem sempre são de fácil diagnóstico. Doenças como câncer, problemas neurológicos, intestinais, renais, hepáticos são enfermidades com pesquisas relacionadas a poluentes na água (CENTENO et al., 2013). A percepção da relação entre o ambiente e a saúde não vem de agora, textos da Medicina Chinesa, datados do período da Dinastia Song (século 1000 a.C.); filósofos pretéritos como Hipócrates (460-377 a.C) e Paracelsus (1493-1541) (SELINUS, 2005). Elementos químicos como chumbo, prata, ouro e outros foram descritos com um potencial tóxico por povos antigos, o que se confirmou com estudos de arqueologistas contemporâneos e historiadores médicos em múmias e cadáveres pré-históricos (DAVIES et al., 2013).

Espécies químicas como mercúrio, chumbo e alumínio, por seu turno, são geralmente tóxicas mesmo sendo possuidores de função biológica para o homem limitada. Caso de excesso de íon nitrato em água pode causar, em recém-nascidos, a síndrome do bebê azul; e em adultos, pode ser responsável por causar câncer de estômago e, em mulheres, aumentar a probabilidade de câncer de mama (AWWA, 1990; BOUCHARD et al., 1992). O íon nitrato, $\mathrm{NO}_{3}{ }^{-}$, como poluente, pode ocorrer em aquíferos de zonas rurais e periferias urbanas. Sua origem pode estar no uso de fertilizantes com nitrogênio aplicados no solo ou em plantações, inorgânicos ou de esterco animal; cultivo do solo; ausência de esgotamento sanitário, levando o rejeito humano para o ambiente e, deposição atmosférica (BAIRD et al., 2011).

A eficiência nas monoculturas se dá pelo uso de fertilizantes sintéticos, porém, o custo ambiental vem na forma desequilibrada do ciclo do nitrogênio, contrabalanceando fatores bióticos e abióticos que, nem sempre, o ambiente está apto a assimilar. Este excedente pode ser carreado por lixiviação para os mananciais próximos ao cultivo, a saber, rios, lagos, lagunas, aquíferos... provocando eutrofização, comprometendo a sua qualidade hídrica (BRAGA et al., 2005). Apesar da indústria produzir herbicidas e pesticidas com menor tempo de vida útil, com processo de decomposição rápida no ambiente, porém, dependendo do tipo de solo e sua capacidade de retenção de poluentes, pode haver a percolação do contaminante pelas camadas do subsolo, atingindo, ocasionalmente a água subterrânea na zona rural (SPIRO et al., 2009).

Neste estudo, objetiva-se avaliar os parâmetros bacteriológicos (coliformes totais e E. Coli), e de espécies químicas inorgânicas nitrogenados (amônia, nitrito e nitrato), nas amostras de água coletadas em poços da rede de abastecimento e outros de construção particular e, a possível relação com doenças de notificação compulsória.

\section{REVISÃO TEÓRICA}

\section{Contaminação das águas subterrâneas e doenças veiculadas}

Fossas sépticas, aplicação de fertilizantes e pesticidas no solo, aterros sanitários, mineração, intrusão marinha e outros, são algumas das formas de contaminação das águas subsuperficiais e que podem atingir o aquífero de forma direta ou indireta. Na forma direta, por meio de poços abandonados ou com deficiência 
construtiva e, de forma indireta, após diluição do contaminante durante a percolação no meio, além de sofrer mudanças físicas, químicas e biológicas durante o trajeto (MANOEL FILHO, 2008).

Isso, por si só, justifica o uso deste tipo de reserva hídrica, devido a maior barreira de contaminação quando comparado às águas de superfície, porém, uma vez contaminado, torna muito mais oneroso a remediação e, não muito incomum, a sua inutilização. Araújo et al. (2013) observaram que dados anômalos hidrogeológicos podem ser correlacionados com algumas endemias na população que se serve desta água.

Os contaminantes, sejam inorgânicos (metais, flúor, selênio, nitratos, radionuclídeos etc), orgânicos (organometálicos, derivados de petróleo, pesticidas, agroquímicos etc) ou biológicos (bactérias e vírus) (ver tabela 1), estão presentes no meio oriundos não só de atividades antrópicas, mas também, como no caso do flúor, arsênio, fósforo e selênio, como constituintes tóxicos naturais.

Tabela 1: Doenças causadas por microrganismos frequentemente relacionadas a ingestão de água contaminada.

\begin{tabular}{ll}
\hline Doenças & Microorganismo causador \\
\hline Cólera & Vibrio cholerae \\
Febre tifoide & Salmonella typhi \\
Gastroenterite & Escherichia coli e outros tipos de salmonella, proteus, derby etc. \\
Diarréia infantil & Tipos enteropatogênicos de Escherichia coli \\
Leptospirose & Leptospira sp.
\end{tabular}
Fonte: Santos (2008).

O ambiente uma vez contaminando, ou a ausência natural de certos constituintes, pode trazer uma série de doenças associadas, que varia com a forma em que a espécie química se apresenta (valência, ligantes, teor de concentração etc). Na dieta humana, dezesseis elementos são fundamentais para funções bioquímicas específicas, dentre estes estão os macronutrientes, necessários na nutrição em concentrações em partes por mil do elemento por massa corpórea, que são: cálcio, fósforo, magnésio, sódio, potássio e cloro, e os micronutrientes, necessários na nutrição em concentrações em partes por milhão ou bilhão do elemento por massa corpórea, caso do: ferro, cobre, zinco, iodo, selênio, manganês, molibdênio, cromo, flúor e cobalto (ingestão humana na forma de vitamina B12) (COMBS JUNIOR, 2013).

Outros seis são usados como suplementos em casos de debilitação, trata-se do níquel, chumbo, arsênio, boro, vanádio e silício. Todos os elementos citados, essenciais ou não, podem trazer danos à saúde humana quando ingeridos em excesso. Alguns são conhecidamente carcinogênicos, como: arsênio e seus compostos inorgânicos, cromo (VI), Níquel e compostos, Cadmio e compostos e o Berílio e compostos (NORDBERG et al., 2013).

\section{Indicadores de contaminação das águas}

Por ser conhecidamente de melhor qualidade, comparado à água superficial, e de baixo custo, têmse uma política de explotação mundial crescente dessas águas, cerca de 1,5 bilhão de pessoas no globo usam esta fonte. Inclusive na América do Sul, tendo como justificativa atender as necessidades sociais e econômicas (BOCANEGRA et al., 2010). Espécies químicas nitrogenadas inorgânicas, precipitam com dificuldade e, podem se estabilizar em ambientes redutores, com Potencial Redox (Eh) negativo. A sua 
capacidade de mobilidade no substrato, associada a efusão, na forma gasosa, permiti a migração das camadas superiores do solo para a água (FEITOSA, 2008).

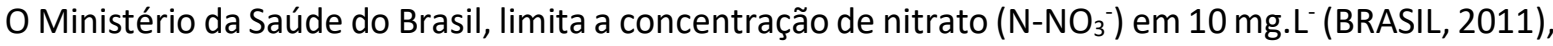
sendo a mesma concentração, como valor máximo permissível (VMP) da Agência de Proteção Ambiental (EPA), dos Estados Unidos. Essa espécie nitrogenada, ocorre em teores, geralmente, no intervalo de 0,1 mg.La 10 mg.L', nas águas subterrâneas, podendo chegar a 1000 mg.L', em águas poluídas.

A amônia $\left(\mathrm{N}-\mathrm{NH}_{3}\right)$ é um indicativo de poluição recente, onde a presença de níveis elevados de nitrogênio amoniacal prejudica a qualidade da água. A conversão da amônia para nitrito, e deste para nitrato resulta em consumo de oxigênio (ARAÚJO et al., 2006). Nitrogênio com alto teor de nitrato e com baixo teor de amônia sugere que a poluição aconteceu há mais tempo (VESILIND, 2013). Substâncias que revelam a presença de fontes poluidoras, como exemplo as bactérias Escherichia coli (E. Coli), como presença indicadora de esgotos no corpo hídrico, nomeiam-se de "indicadores de poluição aquática" (MANAHAN, 2013).

Os poços por serem construções ligadas diretamente ao aquífero são considerados meios de contaminação indireta de um aquífero. Problemas de engenharia, e de manutenção, podem ocasionar a contaminação da água de um aquífero mais profundo pela entrada de sedimentos e água contaminada (FEITOSA, 2008). Acidentes como, rompimento de fossas sépticas e tubulação da rede de esgoto, não são incomuns. Permitindo assim, a contaminação e poluição da água por compostos ricos em, nitrogênio, fósforo e metais pesados (CASTANY, 1975).

Os efluentes industriais e domésticos, apresentam em sua composição, uma ampla lista de poluentes, orgânicos e inorgânicos. Exemplos presentes em vasta literatura são: os compostos orgânicos refratários, vírus, bactérias patogênicas, detergentes, fosfatos, graxas e óleos, sais, metais, agentes quelantes, sedimentos, objetos flutuantes, nitrato etc. (GONÇALVES et al., 1997).

\section{Caracterização Física de Icapuí}

Em estudo litoestratigráfico, feito por Sousa (2002), ao definir um cenário das ocorrências nas falésias costeiras de Icapuí e leste de Aracati, observou o domínio, nas falésias, de rochas siliciclásticas, na base e na parte superior, das formações: Barreiras (base), Potengi (topo) e, já em Aracati, Tibau (base). Com presença localizada, a oeste de Ponta Grossa, de carbonatos na base das falésias oriundos da Formação Jandaíra, unidade mais antiga. A planície costeira de Icapuí, está inserida no bioma Caatinga, com complexos vegetacionais litorâneos específicos, amplamente representados pela mata de tabuleiro e ecossistema manguezal (MEIRELES et al., 2012).

O Tabuleiro litorâneo é o relevo predominante do município e, quase sempre, encontra-se coberto por dunas antigas - Formação Potengi (SANTOS, 2012). Seu limite interior marca o contato entre sedimentos tipicamente continentais (inconsolidados, arenosos e de coloração variegada) com os da planície costeira, delimitado por uma falésia morta. O litoral de Icapuí, não diferente de outros municípios do litoral leste do Estado do Ceará, possui as maiores medidas de precipitações pluviométricas, em média da série histórica, 
registradas no período chuvoso, de janeiro a maio, com destaque para os meses de março e abril, que no período entre 1988 e 2015, suas médias históricas, foram de 223,46mm e 225,83mm, respectivamente.

O clima é Tropical Quente Semiárido Brando, com temperaturas em média de 26,1-28,3드, com máximas entre $30^{\circ} \mathrm{C}$ a $31^{\circ} \mathrm{C}$, e pluviosidade anual total, com média de $914,62 \mathrm{~mm}$, segundo a Série histórica 1988-2015. O aquífero de Icapuí pertence a Bacia hidrográfica do Atlântico Sul-N/NE na Sub-bacia hidrográfica do Rio Jaguaribe, com 68 poços cadastrados na base de dados do Sistema de Informações de Águas Subterrâneas - SIAGAS, destes, apenas 35 ativos, de acordo com o mesmo órgão. O fluxo subterrâneo do local é regulado pelas lagoas, laguna, banco de algas e estuários e, se encontram dispostas ao longo da planície. Lagos interdunares, observadas no campo de dunas e, lagoas costeiras, formadas entre sulcos e cavas dos cordões litorâneos nos terraços marinhos holocênicos, sofrem variação de nível d'água sazonal, períodos de chuva e estiagem.

Meireles et al. (2012) afirmam a tendência de as lagoas sobre os terraços marinhos serem salobras, provavelmente por conexão com a cunha salina e, por observarem dados morfológicos como: proveniência de sedimentos das falésias, hidrodinâmica relacionada com a aportação de água doce do aquífero (nascentes e olhos dágua dos 'morros' entre Ibicuitaba e a Serra da Mutamba) e os eventos de mudanças do nível do mar.

\section{Saúde do município de Icapuí/CE}

Icapuí possui 11 unidades de saúde ligadas ao Sistema único de Saúde - SUS, e todas pertencem ao poder público. Contando com apenas 143 profissionais de saúde, sendo que destes, 10 são médicos, 5 dentistas, 16 enfermeiros e 40 agentes de saúde (IPECE, 2014). Uma comparação com a média do estado pode ser observada na Tabela 2.

Tabela 2: Principais indicadores de saúde do município de Icapuí em relação ao Ceará em 2013.

\begin{tabular}{lll}
\hline Discriminação & Município & Estado \\
\hline Médicos/1000hab. & 0,52 & 1,27 \\
dentistas/1000hab. & 0,21 & 0,34 \\
leitos/1000hab. & 0,73 & 2,37 \\
Unidades de saúde/1000hab. & 0,58 & 0,42 \\
Taxa de internação por AVC (40 anos ou mais)/10000hab. & 3,44 & 28,28 \\
Nascidos vivos & 161 & 124.583 \\
Óbitos & 2 & 1.564 \\
Taxa de mortalidade infantil/1000 nascidos vivos & 12,42 & 12,55 \\
\hline
\end{tabular}
Fonte: IPECE (2014).

Índices de doenças de veiculação hídrica geralmente são altos em locais onde condições de urbanização, habitação e de saneamento básico são precárias. Algumas delas devem ser comunicadas às autoridades de saúde em no máximo 24 horas (exemplos: cólera, óbitos por dengue, febre tifóide) e outras em até sete dias horas (exemplos: casos de dengue, hepatites virais). Doenças de Notificação Compulsória DNC, como: cólera, coqueluche, difteria, dengue, febre tifóide, hepatites virais, leishmanioses, leptospirose, meningites, além da melioidose, considerada de notificação compulsória no Ceará. Podem ser controladas e 
prevenidas por meio de: Acesso a meios de prevenção; Vacinas; Acesso ao tratamento; Assistência pré-natal; Saneamento e Redução das desigualdades sociais.

Contando com uma população que se aproxima dos 20 mil habitantes e com mais de 5.200 residências permanentes, o município de Icapuí, tem na gestão da oferta d'água e na ausência da rede coletora de esgoto problemas pontuais de destaque. Enquanto a oferta de serviços de abastecimento de água pela rede geral de distribuição alcança $82 \%$ das residências do município, com outros 5,55\% atendidos por poço ou nascente na propriedade, de forma contraditória, apenas 29 residências estão ligadas à rede geral de esgotos ou à rede de drenagem pluvial, com outras 753 residências servidas por fossa séptica (IBGE, 2010).

Outra atividade que se utiliza, de forma bastante intensa, dos recursos hídricos da região é a carcinicultura. $\mathrm{O}$ cultivo de camarão em tanques necessita a retirada de parte da água doce local e, que após o seu uso é descartada, com o devido tratamento do efluente. Para garantir tais obrigações são exigidas, por parte dos órgãos ambientais, análises físicas, químicas e biológicas da água que entra na fazenda e da sua saída, visto que os rejeitos do animal mais a ração e as espécies mortas produzem um aumento do teor de matéria orgânica no corpo hídrico, tal material particulado no rio pode capturar metais presentes por emissão dos efluentes domésticos, como zinco e cobre, e num processo de retroalimentação, voltar ao tanque da fazenda e ser assimilado pelo camarão (LACERDA et al., 2004).

\section{METODOLOGIA}

\section{Área de Estudo}

O município de Icapuí fica no extremo leste do estado do Ceará (Mapa 1) entre as coordenadas geográficas longitudinais $39^{\circ} 30^{\prime} \mathrm{W}$ e $37^{\circ} 00^{\prime} \mathrm{W}$ e latitudes $05^{\circ} 00^{\prime} \mathrm{S}$ e $03^{\circ} 30^{\prime} \mathrm{S}$, distante, em linha reta, $166 \mathrm{~km}$ da capital do Estado do Ceará, Fortaleza. Limítrofe ao norte e ao leste com o Oceano Atlântico, ao sul e oeste com o município de Aracati-CE e, com o Estado do Rio Grande do Norte, também ao sul (IPECE, 2014).

Seu território se estende ao longo de $64 \mathrm{~km}$, com uma área de 423,4 $\mathrm{km}^{2}$ e uma densidade demográfica de 43,43 hab/ $\mathrm{km}^{2}$, com um litoral de $40 \mathrm{~km}$ e, uma população estimada em 2013 de 19.129 habitantes. $O$ acesso, via terrestre, para o município de Icapuí, com saída de Fortaleza, pode ser feito pela CE-040 até a cidade de Aracati e então pegar a BR-304 até a CE-261 (conhecido como triângulo). Outra via pode ser por meio da BR-116 até localidade conhecida como Boqueirão do Cesário (pertencente a Beberibe) e tomar a BR-304, passar por Aracati e entrar no acesso a Icapuí/CE-261.

A escolha dos poços deu-se por uso, para o consumo humano e, serviço, pertencentes a rede de distribuição de água para a comunidade ou de construção particular. Os poços foram catalogados e plotados (ver mapa 1) como IS01, IS02, IS03, IS04, IS05, IS06, IS07, IS08, IS09, IS10, IS11, IS12, IS13, IS14, IS15, IS16, IS17, foram plotados por um aparelho de navegação portátil - GPS (Global Position System) modelo GARMIN com o sistema de referência SAD69-South American Datum. 


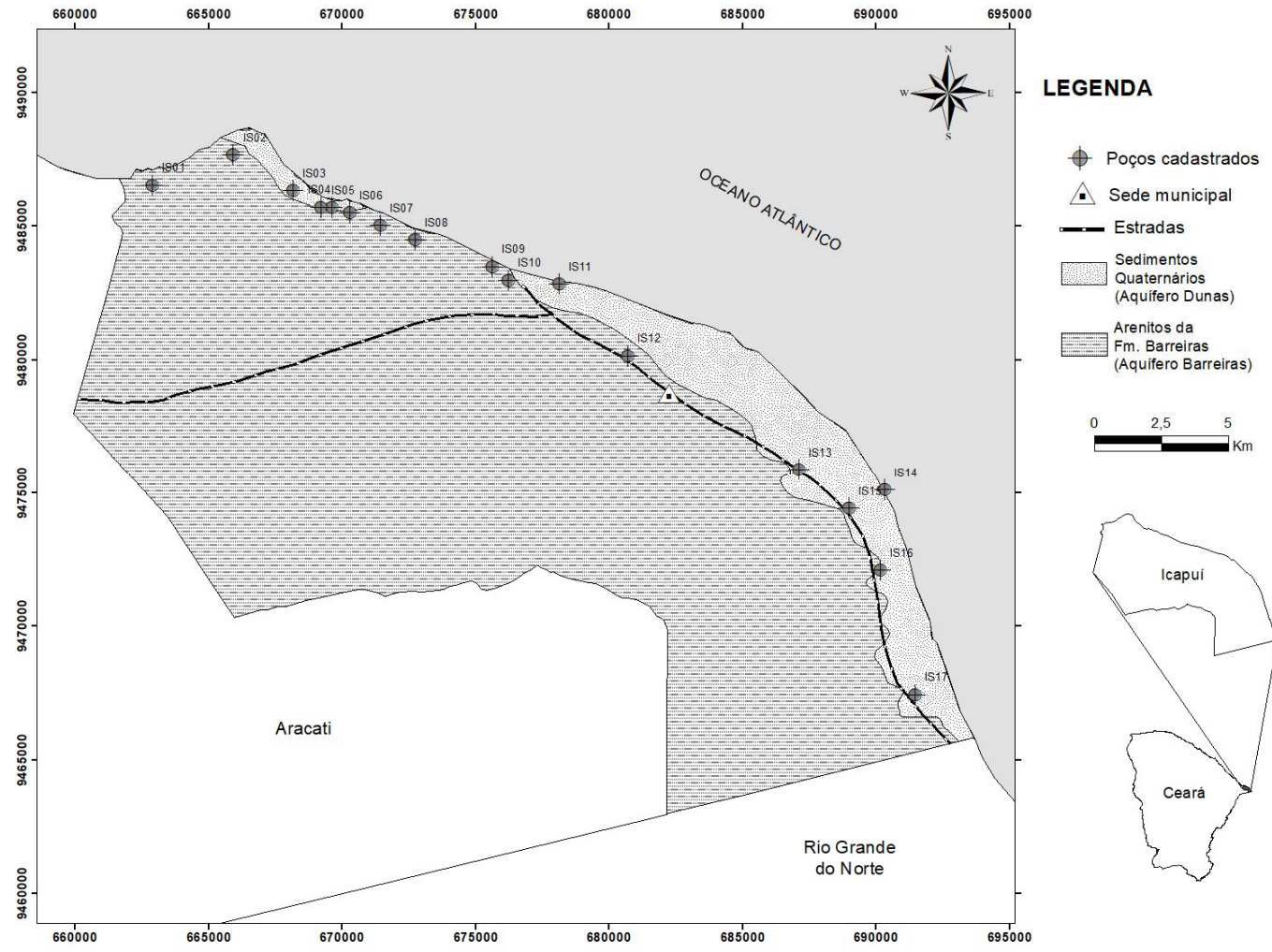

Mapa 1: Localização da área de estudo e distribuição dos poços nos sistemas aquíferos. Fonte: CPRM (2003).

\section{Amostragem de Água}

Foram realizadas quatro campanhas de amostragem, nos períodos abrangidos por época chuvosa e estiagem, anos de 2014 (novembro) e 2015 (novembro). Organizando-se os frascos para coletas, todos devidamente descontaminados, rotulados e selecionados para um melhor controle e agilidade no trabalho. Para a investigação da área foram coletadas 17 amostras de água de poços subterrâneos. Os reservatórios destinados à água para análise bacteriológica foram esterilizados e, após a coleta, mantidos sob refrigeração. As coletas da água foram realizadas após cinco minutos de funcionamento do motor do poço, prática utilizada com o intuito de descartar e se evitar conter na amostra, água estagnada e/ou contaminada, não representativa do aquífero, pela tubulação.

\section{Procedimento Analítico}

As técnicas analíticas utilizadas correspondem a métodos já rotineiros do Laboratório de Geoquímica Ambiental - LGA da Universidade Federal do Ceará, com a realização/acompanhamento de técnicos da UFC.

\section{Análise bacteriológica}

O procedimento requer primeiro a esterilização do local de saída da água, utilizando-se de algodão em chamas, embebido em álcool, em seguida, os frascos foram fechados e acondicionados em isopor com bolsas térmicas, mantendo-as resfriadas. 0 procedimento analítico foi realizado em menos de 48 horas após as coletas das amostras, com o objetivo principal de detectar bactérias do grupo dos coliformes fecais.

No laboratório, LGA, as amostras foram filtradas a vácuo, por meio de membrana filtrante, de éster de celulose (porosidade $-0,45 \mu \mathrm{m}$ ) com reticulado e $47 \mathrm{~mm}$ de diâmetro. A membrana foi acondicionada em 
Placas de Petri contendo meio de cultura nutritivo, seletivo para coliformes e, imediatamente, acondicionadas na estufa de incubação a uma temperatura de 36드, por um período de 24 horas, sendo depois levada à contagem visual das colônias de coliformes (representadas por pontos de coloração verdes e azuis) por meio de fluorescência ultravioleta. A contagem de UFC's (Unidade Formadoras de Colônias) foi realizada da seguinte forma: pontos fluorescentes à luz ultravioleta indicam a presença de colônias de bactéria E. Coli e, pontos azuis, opacos, as colônias de Coliformes Totais (APHA, 2005)

\section{Análise de compostos nitrogenados inorgânicos na água subterrânea Nitrato $\left(\mathrm{N}-\mathrm{NO}_{3}{ }^{-}\right), \mathrm{Nitrito}\left(\mathrm{N}-\mathrm{NO}_{2}{ }^{-}\right)$e amônia $\left(\mathrm{N}-\mathrm{NH}_{3}\right)$}

Na determinação da concentração do nitrato foi empregado o método da coluna redutora de cádmio (Quadro 1), o qual consiste na conversão do nitrato $\left(\mathrm{NO}_{3}{ }^{-}\right)$em nitrito $\left(\mathrm{NO}_{2}{ }^{-}\right)$, por contato da amostra com grãos de cádmios tratados com cobre ( $\mathrm{Cd}-\mathrm{Cu})$, obtendo-se a soma das concentrações em nitrato e nitrito (APHA, 2005). A concentração em nitrato pode ser obtida pela subtração da concentração em nitrito. A determinação do nitrito envolvemos procedimentos espectrofotométricos baseados na reação de Griess, na qual o nitrito reage com a sulfanilamida em meio ácido.

$\mathrm{O}$ nitrogênio amoniacal total $\left(\mathrm{N}-\mathrm{NH}_{3}\right)$ foi determinado pelo método Fenato (Quadro 1), no qual um composto de cor azul formado pela reação da amônia com hipoclorito e fenol, sendo estável por mais de 24h. O hipoclorito foi substituído por dicloisocianurato sódico dihidratado, conforme Aminot et al. (1983) e Aminot et al. (2004). A análise da amônia iniciou-se in situ com a adição dos reagentes - R1 (reagente de fenol) e R2 (reagente de citrato de sódio) - a amostra imediatamente após a coleta. Estas amostras foram mantidas ao abrigo da luz até a chegada ao laboratório para leituras das absorbâncias a 630nm.

Quadro 1: Métodos analíticos aplicados.

\begin{tabular}{|lll|}
\hline Medida / Análise & Método aplicado & Código \\
\hline Nitrato $\left(\mathrm{N}-\mathrm{NO}_{3}{ }^{-}\right)$ & Coluna redutora de Cádmio & $4500 \mathrm{E}$ \\
Nitrito $\left(\mathrm{N}-\mathrm{NO}_{2}{ }^{-}\right)$ & Colorimétrico & $4500 \mathrm{~B}$ \\
Amônia $\left(\mathrm{NH}_{3}\right)$ & Fenato & $4500 \mathrm{~F}$ \\
\hline
\end{tabular}

\section{RESULTADOS E DISCUSSÃO}

Dezoito por cento (18\%) dos poços, sendo específico, poços IS01, IS04 e IS13 apresentaram, em suas amostras, teores de nitrato acima do permitido (Tabela 3). Desses, apenas o poço IS04 não pertence a rede de abastecimento. O poço ISO1 fica em cima da falésia e dentro da comunidade de Retiro, é administrado pelo SERVIÇO DE ABASTECIMENTO DE ÁGUA E ESGOTO - SAAE - Icapuí aos cuidados do Sr. Miquéias. Tem a forma tubular com bomba submersa, seu uso para o abastecimento das residências. Observou-se no seu entorno, criação de galináceos e fossas sépticas de residências. A água, após o processo de dessalinização, abastece aquela comunidade que fica na extremidade ocidental e próximo à divisa com o município de Aracati.

O poço ISO4 é de propriedade particular do Sr. Eduardo, pescador da comunidade de redonda que utiliza essa água para fabricação do gelo utilizado nos embarques pesqueiros, consumo da tribulação e, em períodos de escassez, consumo na sua residência. Muito provável que a contaminação seja pela proximidade 
das fossas sépticas e não manutenção/construção adequada do poço. O poço IS13 abastece o distrito de Ibicuitaba, de uso múltiplo, localizado dentro de uma escola municipal, possui poucos dados incompletos de construção no sítio da CPRM, como, por exemplo, sua profundidade, que é de $67 \mathrm{~m}$. De propriedade da prefeitura e, também, administrado pelo SAAE- Icapuí.

Tabela 3: Teores médios de $\mathrm{N}$-nitrato, $\mathrm{N}$-nitrito e $\mathrm{N}$-amoniacal, em $\mathrm{mg} \cdot \mathrm{L}^{-1}$, nas águas dos poços coletadas nos períodos de nov/14, mar/15, jun/15 e nov/15.

\begin{tabular}{|c|c|c|c|c|c|c|}
\hline $\begin{array}{l}\text { POÇOS } \\
\text { VMP* }\end{array}$ & $\begin{array}{l}\text { N-nitrato } \\
10\end{array}$ & DMP & $\begin{array}{l}\mathrm{N} \text {-nitrito } \\
1\end{array}$ & DMP & $\begin{array}{l}\mathrm{N} \text {-amoniacal } \\
1,5\end{array}$ & DMP \\
\hline IS01 & 10,5 & 1,80 & $<0,001$ & 0 & 0,1 & 0 \\
\hline ISO2 & 7,8 & 0,73 & $<0,001$ & 0 & 0,05 & 0,05 \\
\hline ISO3 & 0,4 & 0,10 & $<0,001$ & 0 & 0,10 & 0 \\
\hline ISO4 & 20,2 & 5,93 & 0,01 & 0 & 0,20 & 0,1 \\
\hline ISO5 & 6,8 & 1,49 & 0,01 & 0 & 0,10 & 0 \\
\hline ISO6 & 8,0 & 0,88 & $<0,001$ & 0 & 0,05 & 0,05 \\
\hline ISO7 & 7,1 & 0,90 & $<0,001$ & 0 & 0,05 & 0,05 \\
\hline ISO8 & 5,3 & 0,45 & $<0,001$ & 0 & 0,05 & 0,05 \\
\hline ISO9 & 0 & 0,00 & $<0,001$ & 0 & 0,10 & 0 \\
\hline IS10 & 5,8 & 1,39 & $<0,001$ & 0 & 0,10 & 0 \\
\hline IS11 & 1,0 & 0,10 & $<0,001$ & 0 & 0,09 & 0,01 \\
\hline IS12 & 5,9 & 3,69 & $<0,001$ & 0 & 0,47 & 0,25 \\
\hline IS13 & 10,1 & 1,88 & $<0,001$ & 0 & 0,10 & 0,1 \\
\hline IS14 & 5,2 & 3,84 & 0,06 & 0,02 & 2,37 & 0,84 \\
\hline IS15 & 3,0 & 1,62 & $<0,001$ & 0 & 0,10 & 0,004 \\
\hline IS16 & 3,9 & 0,20 & $<0,001$ & 0 & 0,10 & 0 \\
\hline IS17 & 3,7 & 1,16 & 0,01 & 0 & 0,10 & 0 \\
\hline
\end{tabular}

Desvio Médio Padrão - DMP; *VMP - Valor máximo permitido para potabilidade em mg.L-1 (Portaria no 2914 do Ministério da Saúde do Brasil de 2011)

Apesar de estar dentro do permitido para o consumo humano, para teores de nitrato, os poços ISO2, IS05, IS07, IS08, IS10, IS12 e IS14 (35\%), possuem concentração de nitrato (expresso em N) acima de 05 mg.L${ }^{1}$, onde, nesta faixa de concentração de 05 a $10 \mathrm{mg} \cdot \mathrm{L}^{-1}$, faz-se necessário ações preventivas e uso de regras para aplicação de resíduos em solos agrícolas, nos processos de licenciamento e fiscalização ambiental (CETESB, 2013), visto que, indicam provável contaminação por atividades antrópicas como: fossas mal estruturadas, esgotamento sanitário danificado, disposição indevida de resíduos sólidos, proximidade de cemitérios etc. Desses poços citados, apenas não pertencem a rede de abastecimento público, os poços, IS10, IS12 e IS14.

O poço IS10, está localizado na comunidade das Barreiras. É de propriedade do Sr. Oliveira. Ele informou que a profundidade do mesmo é de $5,5 \mathrm{~m}$. O seu uso é para o consumo da casa. Muitas casas próximas e nenhuma com o esgotamento sanitário, justifica a presença de nitrato anômala para águas subterrâneas. Já o poço IS12, fica na zona urbana, na sede do município, e pertence a uma propriedade particular. A falta de esgotamento sanitário na sede justifica sua concentração de nitrato.

A água do poço IS14, com presença de nitrogênio amoniacal acima do permitido $(0,6 \%$ dos poços amostrados), deve-se a falta de cuidado com o mesmo, estava em situação praticamente de abandono. Localizado na praia de Tremembé, de uso dos moradores da praia e, com 4,5m de profundidade. Os demais poços, são gerenciados pelo SAAE - Icapuí, e abastecem as comunidades de Redonda, Requenguela, Picos, Peroba, e a sede. 
Mesmo com baixa densidade demográfica, 43,43 hab/ $\mathrm{km}^{2}$, o aquífero pode estar comprometido, visto que $59 \%$ dos poços estudados requerem manejos de práticas ambientais devido o teor de nitrato em sua composição química. Maia e colaboradores (2017) mostram os possíveis impactos negativos causados no município por explotação dos poços do aquífero costeiro, apesar de minimizados por estarem, em sua maioria, construídos sobre a Formação Barreiras, onde a presença de argila no solo dificulta o gradiente de contaminantes até o aquífero.

Ao compararmos os resultados deste estudo para nitrato com outros, como, por exemplo, o realizado por Dovidauskas et al. (2015) na cidade de Monte Azul Paulista, uma cidade com densidade demográfica, $71,86 \mathrm{hab} / \mathrm{km}^{2}$, encontrou $50 \%$ dos poços, contaminados com N-nitrato, em área urbana antiga. No estudo, Dovidauskas e colaboradores, mesmo encontrando vazamento na rede coletora de esgoto, somado a isso, um adensamento populacional maior, observa-se os teores medidos para nitrato, $0,3-16,4 \mathrm{mg} \cdot \mathrm{L}^{-1} \mathrm{se}$ aproximam aos de Icapuí, 0,0-20,2 mg. $\mathrm{L}^{-1}$, o que confirma a contaminação por proximidade de fossas sépticas e negras.

Fernandes et al. (2010), encontrou na região do semiárido cearense, valores entre 0,0 mg. L $^{-1}$ a 83,0 mg. $\mathrm{L}^{-1}$, apesar da baixa média de pluviosidade anual, $725,4 \mathrm{~mm}$, os teores altos, de nitrato, paradoxal a pouca lixiviação do solo, pode estar associado ao uso excessivo de fertilizantes inorgânicos nitrogenados. Frizzo (2006), encontrou no município vizinho, Aracati, valores entre 10,0 a $30,0 \mathrm{mg} \cdot \mathrm{L}^{-1}$ de $\mathrm{N}$-nitrato, em poços tubulares da rede de abastecimento público, o que demonstra a falha na manutenção e/ou construção dos poços no extremo litoral leste do Ceará e falta, também, de medidas de prevenção, já citadas em parágrafos anteriores.

As amostras de água dos poços IS01, IS04, IS11, IS12, IS13, IS14 e IS15, apresentaram-se impróprias para o consumo humano no período de chuvas, devido a presença de bactérias na água (Tabela 4). Contabilizando $41 \%$ da amostragem bacteriológica. A pouca profundidade dos poços, erros na construção e a má manutenção dos mesmos, podem permitir a contaminação pela lixiviação do solo. O poço IS11, está localizado no Chalés do Mar, na Praia de Barreiras de Cima, o qual é de propriedade particular, Sr. Luís Gonzaga, na forma tubular com bomba injetora. Ele informou a profundidade do mesmo de $9 \mathrm{~m}$. Apesar de fazer uso constante de cloro, sua água apresentou presença de coliformes totais, na primeira amostragem, muito provável por um descuido na manutenção. O poço IS15 está localizado na comunidade de Melancias de baixo, o qual é de propriedade particular, na forma tubular com bomba injetora. O seu uso é para fins domésticos. Algumas casas próximas e nenhuma com o esgotamento sanitário.

A presença de E. Coli na água coletada no poço IS13, mesmo sendo em apenas uma das campanhas, é bastante preocupante e surpreendente, por ser um poço administrado pelo SAAE-Icapuí, de outra maneira, por abastecer um distrito, Ibicuitaba, e encontrar-se dentro de zona urbana, esse indicativo de contaminação por fezes humanas torna necessária uma investigação nas construções de fossas sépticas na escola e residências próximas. 
Tabela 4: Quantidade de colônias de bactérias coliformes totais (UFC/100mL) e bactérias E. Coli (UFC/100mL) nos poços do estudo ao longo de 2015.

\begin{tabular}{|c|c|c|c|c|c|c|}
\hline \multirow[t]{2}{*}{ POÇOS } & \multicolumn{2}{|c|}{ MAR/15 } & \multicolumn{2}{|c|}{ JUN/15 } & \multicolumn{2}{|c|}{ NOV/15 } \\
\hline & CT & EC & CT & EC & CT & EC \\
\hline ISO1 & 10 & 00 & 00 & 00 & 00 & 00 \\
\hline ISO2 & 00 & 00 & 00 & 00 & 00 & 00 \\
\hline ISO3 & 00 & 00 & 00 & 00 & 00 & 00 \\
\hline ISO4 & 90 & 00 & 00 & 00 & 00 & 00 \\
\hline ISO5 & 00 & 00 & 00 & 00 & 00 & 00 \\
\hline ISO6 & 00 & 00 & 00 & 00 & 00 & 00 \\
\hline ISO7 & 00 & 00 & 00 & 00 & 00 & 00 \\
\hline ISO8 & 00 & 00 & 00 & 00 & 00 & 00 \\
\hline ISO9 & 00 & 00 & 00 & 00 & 00 & 00 \\
\hline IS10 & 00 & 00 & 00 & 00 & 00 & 00 \\
\hline IS11 & 100 & 20 & 00 & 00 & 00 & 00 \\
\hline IS12 & 30 & 00 & 00 & 00 & 00 & 00 \\
\hline IS13 & 00 & 00 & 00 & 00 & 00 & 01 \\
\hline IS14 & 600 & 00 & 00 & 00 & 00 & 00 \\
\hline IS15 & 10 & 00 & 00 & 00 & 00 & 00 \\
\hline IS16 & 00 & 00 & 00 & 00 & 00 & 00 \\
\hline IS17 & 00 & 00 & 00 & 00 & 00 & 00 \\
\hline
\end{tabular}

CT - Coliformes totais; EC - E. Coli.

Um melhor detalhamento dos indicadores de contaminação nas águas dos poços do estudo pode-se observar no mapa 2.

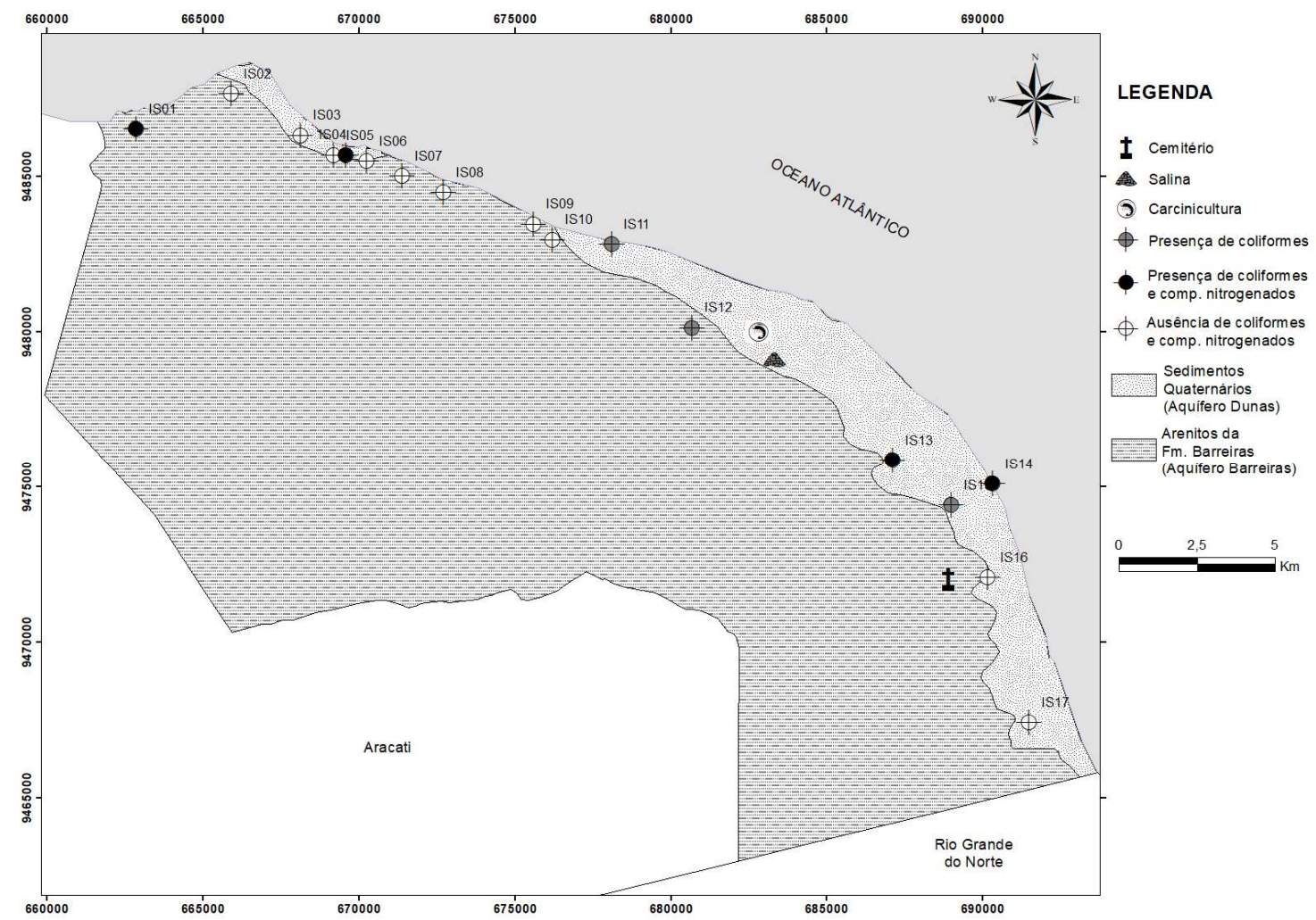

Mapa 2: Distribuição das anomalias hidroquímicas nas águas dos poços estudados. Fonte: CPRM (2003).

Casos confirmados de doenças de notificação compulsória como meningite e hepatite viral, registradas no município (Tabela 5) e, assim como, casos de doenças diarreicas (Tabela 6), favorecem a relação, não tão direta, com os resultados bacteriológicos encontrados nas coletas (Tabela 4). Visto que, a presença desses indicadores bacteriológicos, podem associar a outros organismos patogênicos (SANTOS, 2008). 
Tabela 5: Casos confirmados das doenças de notificação compulsória em Icapuí 2010-2014.

\begin{tabular}{llllll}
\hline Ano & Dengue & Hanseníase & Tuberculose & Hepatite viral & Meningite \\
\hline 2010 & 01 & 00 & 03 & 00 & 00 \\
2011 & 11 & 00 & 04 & 00 & 00 \\
2012 & 19 & 01 & 02 & 00 & 00 \\
2013 & 11 & 00 & 02 & $00^{*}$ & 01 \\
2014 & 01 & 00 & 03 & $02 *$ & 00 \\
\hline
\end{tabular}

*Segundo a Secretaria de Saúde de Icapuí/CE (MINISTÉRIO DA SAÚDE - SINAN de 2016). Fonte: IPECE (2014).

Segundo matéria veiculada no jornal local, Diário do Nordeste (2016), do dia 16 de abril de 2016, os casos confirmados no Estado do Ceará, nos três primeiros meses do ano, já ultrapassam 120 mil casos de diarreia, superando a metade dos dados do ano passado. Icapuí, até o dia 12 de dezembro de 2016, segundo a Secretaria de Saúde do município, apresenta 630 casos. Tais dados podem ser associados a má qualidade da água servida a população, mas, também, pode indicar uma falta de cuidados na higiene pessoal6

Tabela 5: Casos confirmados de doenças diarreicas agudas em Icapuí 2006-2015

\begin{tabular}{lllllllllll}
\hline Anos & 2006 & 2007 & 2008 & 2009 & 2010 & 2011 & 2012 & 2013 & 2014 & 2015 \\
\hline Casos & 1093 & 818 & 609 & 425 & 549 & 800 & 495 & 515 & 390 & 501 \\
\hline
\end{tabular}

Fonte: Secretaria de Saúde de Icapuí MINISTÉRIO DA SAÚDE - SIVEP-DDA de 2016.

\section{CONCLUSÕES}

O uso da água nos permite relativizar o critério de poluição. No Brasil, a Portaria $n^{\circ} 2.914$, de 12 de dezembro de 2011, do Ministério da Saúde (MS) dispõe sobre os procedimentos de controle e de vigilância de qualidade da água para consumo humano e seu padrão de potabilidade (BRASIL, 2011). Os parâmetros utilizados pela portaria do MS, suas quantificações e enquadramentos, são revistos e atualizados em função da evolução científica e tecnológica.

Atualmente, tal ciência tem tido maior divulgação e preocupação em escala global, devido, principalmente, aos avanços na fiscalização e autuação de órgãos ambientais, assim como, empresas/indústrias também estão atentas e imbuídas em descobrir o verdadeiro vilão. Conhecer e determinar o agente causador de doenças ou eventos de saúde, das mais diversas e que às vezes, são classificadas como epidemias, ultrapassando fronteiras e causando conflito político, tornou-se uma meta internacional.

Apesar de possuir serviço de distribuição de água em rede, a população local, continua construindo poços artesanais e, um dos argumentos utilizados pelos munícipes, é o sabor da água, que pode estar relacionado ao paladar dos mais antigos ou, a turbidez acima do permitido na água (valores acima de 5uT foram encontrados em todas as amostras de água). Esse consumo direto da água de poço particular, pode ser o causador das doenças diarreicas.

A presença de bactérias, E. coli e coliformes totais, e de compostos nitrogenados, nas análises de águas coletadas em alguns poços da rede, justifica o aumento dos casos, em Icapuí, de doenças diarreicas, período entre 2014 a 2015, e o reaparecimento da hepatite viral. Mesmo com a pluviosidade anual abaixo da média histórica, sendo registrado 596mm em 2014 e 610mm em 2015. A contaminação por nitrato, e a não presença de valores anômalos para amônia, nos poços IS01, ISO4 e 1S13, permite afirmar que a poluição 
não é recente e notadamente influenciada por um solo saturado de rejeitos humanos e animais de criação. Visto que não se têm a presença de cultivos próximos que justificassem a aplicação de fertilizantes.

Como o poço IS14, apresentou valores acima e/ou preocupantes em todos indicadores, sugere-se a comunidade de Tremembé a inativação do mesmo. Já o poço IS16, próximo do cemitério, 200m, mostra que a litologia do local reteve os contaminantes estudados, porém, faz se necessária análise de metais traço para viabilizar o mesmo. A presença de bactérias em algumas amostras é preocupante e pode estar associada a patogênicos que justificam doenças no trato gastrointestinal. Pesquisas com médicos sanitaristas serão necessárias para um diagnóstico preciso, entendemos que, os exames dos níveis de nitrato em água precisam ser ampliados, com coletas periódicas de amostras de água, realização do levantamento de dados sobre o câncer gastrointestinal e outras patologias associadas ao tema. Permitindo um zoneamento das espécies nitrogenadas e bacteriológicas, contribuindo para a divulgação científica e proteção da saúde comunitária, fomentando os dados da Secretaria de Saúde, possibilitando políticas públicas eficazes.

AGRADECIMENTOS: A Rede PRODEMA, pelo aporte financeiro em diárias, necessária a realização de viagens ao local de pesquisa e, à FUNCAP, Fundação Cearense de Apoio ao Desenvolvimento Científico e Tecnológico, pela bolsa de doutorado de Saulo R. R. Maia.

\section{REFERÊNCIAS}

AMINOT, A.; CHAUSSEPIED, M.. Manual des Analyses Chimiques en Milieu Mari, Brest: CNEXO, 1983.

AMINOT, A.; KÉROUEL, R.. Hydrologie des écosystèmes marins. Paramètres et analyses. Ifremer, 2004.

APHA. Standard Methods for the Examination of Water and Wastewater, 21 edn. Washington: American Public Healt Association, 2005.

ARAÚJO, F. F. V.; CASTRO, M. A. H.; FIGUEIRÊDO, M. C. B.. Avaliação de impactos dos efluentes da carcinicultura em trecho do Rio Jaguaribe por meio de simulação. In: GESTÃO SUSTENTÁVEL NO BAIXO JAGUARIBE, CEARÁ. Anais. Fortaleza: EMBRAPA - Agroindústria Tropical, 2006. p.151176.

ARAÚJO, P. R.; PINESE, J. P. P.. Anomalias na distribuição geográfica dos dados de saúde da bacia hidrográfica do Ribeirão Lindóia, zona norte do município de Londrina/PR. Confins-Revue franco-brésilienne de géographie/Revista franco-brasilera de geografia, n.17, 2013.

AWWA. American Water Works Association. Water quality and treatment: a handbook of community water supplies. 4 ed. New York: McGraw Hill, 1990.

BAIRD, C.; CANN, M.. Química Ambiental. 4 ed. Porto Alegre: Bookman, 2011.

BOUCHARD, D. C.; WILLIANS, M. K.; SURAMPALLI, R. Y. Nitrate contamination of ground water: sources and potencial health effects. J. Am. Water Works Ass., v.84, n.1, p.85-90, 1992.
BRAGA, B.; HESPANHOL, I.. Introdução à engenharia ambiental: o desafio do desenvolvimento sustentável. 2 ed. São Paulo: Pearson Prentice Hall, 2005.

BRASIL. Ministério da Saúde. Portaria MS n 2.914/2011. Brasília: Ministério da Saúde, 2011.

BOCANEGRA, E.; SILVA JUNIOR, G. C.; CUSTODIO, E.; MANZANO, M.; MONTENEGRO, S.. State of knowledge of coastal aquifer management in South America. Hydrogeology Journal, v.18, n.1, p.261-267, 2010.

CASTANY, G.. Prospeccion y exploracion de las aguas subterraneas. Barcelona: Omega, 1975.

CENTENO, J. A.; MULLICK, F. G.; ISHAK, K. G.; FRANKS, T. J.; BURKE, A. P.; KOSS, M. N.; PERL, D. P.; TCHOUNWOU, P. B.; PESTANER, J. P.. Environmental Pathology. In: SELINUS, O.. Essentials of Medical Geology: Revised Edition, Springer Science: Business Media Dordrecht, 2013. DOI: http://10.1007/978-94-007-4375-5 25

CETESB. Companhia Ambiental do Estado de São Paulo. Qualidade das águas subterrâneas do Estado de São Paulo 2010-2012. São Paulo: Companhia Ambiental do Estado de São Paulo, 2013.

COMBS JUNIOR, G. F.. Geological Impacts on Nutrition. In: SELINUS, O.. Essentials of Medical Geology: Revised Edition, Springer Science: Business Media Dordrecht, 2013. DOI: http://179-194.10.1007/978-94-007-4375-5 8

CPRM. Serviço Geológico do Brasil. Mapa Geológico do Estado do Ceará: Escala 1:500.000. 2003. 
DAVIES, B. E.; BOWMAN, C.; DAVIES, T. C.; SELINUS, O.. Medical Geology: Perspectives and Prospects. In: SELINUS, O.. Essentials of Medical Geology: Revised Edition, Springer Science: Business Media Dordrecht, 2013. DOI: http://10.1007/978-94-007-4375-5 1

DOVIDAUSKAS, S.; OKADA, I. A.; SOUZA, J. A.; NOVAS, M. A. J. H.; ROSSATO, R. A.. A interação entre Vigilância Sanitária e Laboratório de Saúde Pública na detecção da contaminação por nitrato em água subterrânea. Vigilância Sanitária em Debate: Sociedade, Ciência \& Tecnologia, v.3, n.1, p.97-104, 2015.

FEITOSA, F. A. C.; MANOEL FILHO, J.; FEITOSA, E. C.; DEMETRIO, J. G. A.. Hidrogeologia: conceitos e aplicações. 3 ed. Revisada e Ampliada: CPRM, 2008.

FERNANDES, F. B. P.; ANDRADE, E. M.; FONTENELE, S. B.; MEIRELES, A. C. M.; RIBEIRO, J. A.. Análise de agrupamento como suporte à gestão qualitativa da água subterrânea no semiárido cearense. Revista Agro@mbiente On-line. v.4, n.2, p.86-95, 2010.

FRIZZO, S. J.. Elementos Químicos em Águas de Abastecimento Público no Estado do Ceará. In: SILVA, C. R. FIGUEIREDO, B. R.; CAPITANI, E. M.; CUNHA, F. G.. Geologia Médica no Brasil: Efeitos dos Materiais e Fatores Geológicos na Saúde Humana, Animal e Meio Ambiente. Rio de Janeiro: CPRM, 2006. p.183-191.

GONÇALVES, F. B.; SOUZA, A. P.. Disposição Oceânica de esgotos sanitários: História, teoria e prática. Rio de Janeiro: ABES, 1997.

IBGE. Instituto Brasileiro de Geografia e Estatística. Censo demográfico 2010. Rio de janeiro, 2010.

IPECE. Instituto de Pesquisa e Estratégia Econômica do Ceará. Perfil Básico Municipal, Fortaleza, 2014.

LACERDA, L. D.; SANTOS, J. A.; MARINS, R. V.; MAIA, S. R. R.; VAISMAN, A. G.. Impacto potencial da emissão antrópica de Cu e Zn sobre a carcinicultura na bacia inferior do Rio Jaguaribe/CE. Revista da ABCC, v.6, n.1, p. 82-86, 2004.

MAIA, S. R. R.; FREIRE, G. S. S.; GOMES, D. F.. Aquífero costeiro de icapuí, Ceará, Brasil: Uma proposta de avaliação ambiental. Revista Ibero-Americana de Ciências Ambientais, v.8, n.3, p.254-267, 2017.

MANAHAN, S. E.. Química Ambiental. 9 ed. Porto alegre: Bookman, 2013.

MANOEL FILHO, J.. Ocorrência das águas subterrâneas. In: FEITOSA, F. A. C.. Hidrogeologia: Conceitos e aplicações. 3 ed. Rio de Janeiro: CPRM, 2008.

MEIRELES, A. J. A.; SANTOS, A. M. F.. Atlas de Icapuí. 1 ed. Fortaleza: Editora Fundação Brasil Cidadão, 2012.

NORDBERG, M.; CHERIAN, M. G.. Biological Responses of Elements. In: SELINUS, O.. Essentials of Medical Geology: Revised Edition, Springer Science: Business Media Dordrecht, 2013. p.195-214. DOI: http://10.1007/978-94007-4375-5 9

SANTOS, A. C.. Noções de hidroquímica. In: FEITOSA, Fernando A. C.. Hidrogeologia: Conceitos e aplicações. 3 ed. Rio de Janeiro: CPRM, 2008, p.325-357.

SANTOS, A. M. F.. Mapas Temáticos como Fundamentos para a Gestão Ambiental da Planície Costeira de Icapuí, Extremo Leste do Ceará. Geosaberes, Fortaleza, v.3, n.6, p.102-114, 2012.

SOUSA, D. C.. Litoestratigrafia e deformação cenozoica na região de Icapuí, Ceará, e implicações para a estruturação de campos de petróleo na borda ocidental da bacia potiguar (NE do Brasil). Tese (Doutorado em Geodinâmica e Geofísica) - Universidade Federal do Rio Grande do Norte, Natal, 2002.

SELINUS, O.. Geologia Médica. In: SILVA, C. R.. Geologia Médica no Brasil: Efeitos dos Materiais e Fatores Geológicos na Saúde Humana, Animal e Meio Ambiente. Rio de Janeiro: CPRM, 2005, p.1-5.

SPIRO, T. G.; STIGLIANI, W. M.. Química ambiental. 2 ed. São Paulo: Pearson Prentice Hall, 2009.

VESILIND, P. A.; MORGAN, S. M.. Introdução à engenharia ambiental. São Paulo: Cengage Learning, 2013.

A CBPC - Companhia Brasileira de Produção Científica (CNPJ: 11.221.422/0001-03) detém os direitos materiais desta publicação. Os direitos referem-se à publicação do trabalho em qualquer parte do mundo, incluindo os direitos às renovações, expansões e disseminações da contribuição, bem como outros direitos subsidiários. Todos os trabalhos publicados eletronicamente poderão posteriormente ser publicados em coletâneas impressas sob coordenação da Sustenere Publishing, da Companhia Brasileira de Produção Científica e seus parceiros autorizados. Os (as) autores (as) preservam os direitos autorais, mas não têm permissão para a publicação da contribuição em outro meio, impresso ou digital, em português ou em tradução. 